\section{Effects of befriending on depressive symptoms: a precautionary note on promising findings}

Mead et al $^{1}$ recently meta-analysed data on the effectiveness of befriending interventions on reducing depressive symptoms. Befriending was defined as a non-professional intervention that provides clients with non-directive, emotionally focused support by one or more individuals; was not psychoeducational or mentoring in nature; and did not constitute formal psychotherapy. Mead et al found that befriending interventions had a modest, statistically significant effect on depressive symptoms within 12 months of randomisation (standardised mean difference $0.27,95 \%$ CI 0.06 to 0.48 , nine studies) and a slightly smaller effect on longer-term outcomes (standardised mean difference $0.18,95 \%$ CI 0.05 to 0.32 , five studies)

As the authors noted, the effect sizes for befriending were essentially equivalent to effect sizes from collaborative care depression interventions in primary care. In a 2006 meta-analysis, Gilbody et $a l^{2}$ reported a short-term (within 6 months) standardised mean difference effect size for symptom reduction from collaborative or enhanced depression care of 0.25 (95\% CI 0.18 to $0.32,35$ studies) and longer-term effect sizes of 0.15 at 2 years post-randomisation ( $95 \% \mathrm{CI}-0.03$ to $0.32,9$ studies) and 0.15 at 5 years post-randomisation (95\% CI 0.001 to 0.30 2 studies). As Mead and colleagues note, the implications of this are important. Befriending or social support interventions could provide a less expensive and potentially 'less medicalised' option of care for patients with mild to moderate symptoms of depression in primary care. Indeed, collaborative care is a complex, multifaceted, expensive organisational intervention that can be difficult to implement outside of research settings. ${ }^{3,4}$

There are caveats, however. As noted by Mead et al, only a small set of heterogeneous studies have examined the effects of befriending interventions on depressive symptoms. Furthermore, funnel plot asymmetry suggested that publication bias may have influenced the estimate of the degree to which befriending may affect depressive symptoms. The authors did not assess the degree to which publication bias may have influenced the results of the meta-analysis. However, if only studies with statistical power of at least 0.70 among the studies with short-term outcomes evaluated by Mead et al are analysed, the resulting synthesised effect estimate is 0.08 (95\% CI -0.06 to 0.21 , four studies), a substantially smaller estimate than that produced by all nine studies $(0.27,95 \%$ CI 0.06 to 0.48$)$. Thus, as noted by Mead et al, more high-quality research is needed on befriending in order to determine the likely benefit to patients in clinical practice.

Meanwhile, the results of the meta-analysis suggest that future research on collaborative care should use a befriending or attention control group. Up to now, collaborative care interventions have been compared with usual care, and it is not known to what degree the effects that have been reported are due to specific effects of the collaborative care intervention versus effects that may come from the substantially increased attention and support received by patients in collaborative care.
1 Mead N, Lester H, Chew-Graham C, Gask L, Bower P. Effects of befriending on depressive symptoms and distress: systematic review and meta-analysis. Br J Psychiatry 2010; 196: 96-101.

2 Gilbody S, Bower P, Fletcher J, Richards D, Sutton AJ. Collaborative care for depression: a cumulative meta-analysis and review of longer-term outcomes. Arch Intern Med 2006; 166: 2314-21.

3 Katon WJ, Seelig M. Population-based care of depression: team care approaches to improving outcomes. J Occup Environ Med 2008; 50: 459-67.

4 Katon W, Unützer J, Wells K, Jones L. Collaborative depression care: history, evolution and ways to enhance dissemination and sustainability. Gen Hosp Psychiatry 2010; in press.

Ghassan El-Baalbaki, Department of Psychiatry, McGill University, and Department of Psychiatry, Jewish General Hospital, 4333 Côte Ste Catherine Road, Montreal, Quebec HST 1E4, Canada. Email: ghassan.elbaalbaki@videotron.ca; Erin Arthurs, Brooke Levis, Department of Psychiatry, McGill University, and Jewish General Hospital, Montreal; Brett D. Thombs, Departments of Psychiatry, Epidemiology \& Biostatistics, Occupational Health, and Medicine (Division of Rheumatology), McGill Univeristy, and Department of Psychiatry, Centre for Clinical Epidemiology and Community Studies, and Division of Rheumatology, Jewish General Hospital, Montreal Quebec, Canada

doi: 10.1192/bjp.197.3.247

Authors' reply: We thank Dr El-Baalbaki and colleagues for their thoughtful comments on our recent paper. We agree with their cautious interpretation of the results of our meta-analysis.

We were interested in their suggestion that befriending serve as a comparator condition for more structured treatments such as collaborative care, to tease out the specific benefits of the latter over and above the general effects of increased attention and support, and to explore the cost-effectiveness of these complex organisational interventions. Although this makes good sense in design terms, it does, however, relegate befriending to the status of comparator rather than active intervention. The recent Mental Health Foundation report The Lonely Society? (www. mentalhealth.org.uk/campaigns/loneliness-and-mental-health/) highlights the impact of loneliness on health, and its findings are supported by the Royal College of Psychiatrists. ${ }^{1}$ We would therefore want to complement Dr El-Baalbaki and colleagues' suggestion with further research specifically exploring the role of befriending as a potential alternative therapeutic intervention for certain groups such as isolated older adults.

1 Royal College of Psychiatrists. RCPsych comments on MHF report 'The Lonely Society?' Royal College of Psychiatrists, May 2010 (http:// www.rcpsych.ac.uk/press/pressreleases2010/thelonelysociety.aspx).

Nicola Mead, NIHR School for Primary Care Research, 5th Floor, Williamson Building University of Manchester, Oxford Road, Manchester M13 9PL, UK. Email: nicki.mead@manchester.ac.uk. Helen Lester, Carolyn Chew-Graham, nicki.mead@manchester.ac.uk. Helen Lester, Carolyn Chew-Graham, Peter Bower, National Primary Care Research and Development Centre, University of Manchester, UK

doi: 10.1192/bjp.197.3.247a

\title{
Correction
}

Help-seeking and receipt of treatment among UK service personnel. BJP, 197, 149-155. Authors' affiliations/correspondence details should read:

Amy C. Iversen, MRCPsych, Lauren van Staden, MA, King's Centre for Military Health Research, King's College London; Jamie Hacker Hughes, PsychD, Academic Centre for Defence Mental Health, King's College London; Tess Browne, BSc, King's Centre for Military Health Research, King's College London; Neil Greenberg, MD, Academic Centre for Defence Mental Health, King's College London; Matthew Hotopf, PhD, Roberto J. Rona, FFPH, Simon Wessely, FMedSci, King's Centre for Military Health Research, King's College London; Graham Thornicroft, PhD, Health Service 
Population Research Department, King's College London; Nicola T. Fear, DPhil (Oxon), Academic Centre for Defence Mental Health, King's College London.

Correspondence: Amy C. Iversen, King's Centre for Military Health Research, King's College London, Weston Education Centre,
Cutcombe Road, London SE5 9RJ, UK. Email: amy.c.iversen@ kcl.ac.uk

The online version of this paper has been corrected in deviation from print and in accordance with this correction.

doi: 10.1192/bjp.197.3.247b

\section{poems \\ by doctors}

\section{Looking Down}

\section{Roy Salole}

They walk into the restaurant,

as if a cloud was over them,

head bowed and looking down

father, mother, and two girls.

The first, 10 years old, is slim and bright.

The other, older, bigger, with tongue

protruding, her Mongolian features

signaling immediately: "Down's!"

Father shepherds the girl to sit

with her back to the crowd.

Daughter looks up to dad

watching intently for secret signals,

And when she speaks too loud

he holds his hand up

and she stops, well trained;

but her sister, embarrassed, looks down,

and her mother, embarrassed, looks down,

and I, embarrassed, look down.

And,

looking down,

I want to say:

"I know how painful it must be."

I want to say:

"I do imagine it to be unbearable."

I want to say:

"I remember, oh yes

I now remember the day,

so long ago

when my friend's child was born

into my hands and I looked down

and saw those same Mongolian features."

I want to say:

"I remember then,

scared and stunned

I looked away."

I want to say,

"I remember then

my friends too, looked away."

I want to say:

"I remember then,

the pain was so unbearable

that we had to look away in denial

not facing what we saw,

for a time,

until we could look up and deal with the pain."

And when I look up again,

I want to say:

"I weep today in sorrow

for your loss and that of my friend's

and I also weep today in gratitude

for the miraculous gift

of my five sons."

Another of Roy's poems was published in the December 2009 issue of the Journal. 